\title{
A comunicação nas novas diretrizes curriculares para o ensino médio
}

\author{
Ismar de Oliveira Soares*
}

\section{Resumo}

O Ministério da Educação acaba de divulgar o documento intitulado "O Novo Ensino Médio", que se faz acompanhar das "Diretrizes Curriculares Nacionais para o Ensino Médio Brasileiro", aprovado pelo Conselho Nacional de Educação, em junho do corrente ano. Com as novas normas legais, o tema da interrelação Comunicação/Tecnologias da Informação/Educação ganha legitimidade.

Palavras-chave: ensino de comunicação; diretrizes curriculares; educação: tecnologias.

\section{Introdução}

O Ministério da Educação acaba de divulgar o documento intitulado "O Novo Ensino Médio", que se faz acompanhar das "Diretrizes Curriculares Nacionais para o Ensino Médio Brasileiro", aprovado pelo Conselho Nacional de Educação, em junho do corrente ano. Com as novas normas legais, o tema da inter-relação Comunicação/Tecnologias da Informação/Educação acaba de ser legitimado, não podendo ser tomado de forma estanque e fragmentada, muito a gosto de certo marketing educacional mais preocupado em vender equipamentos do que em implementar reformas profundas e substanciais nos modelos e processos educativos.

Segundo as novas disposições, a aproximação entre a Comunicação e a Educação se dá, inicialmente, em suas interfaces com as Artes. É o que se define como "Estética da Sensibilidade", uma das consignas a partir das quais deverá ser construído o novo ensino médio: "Estética da sensibilidade não é um princípio inspirador apenas do ensino de conteúdos ou das atividades expressivas, mas uma atitude diante

* Professor da Escola de Comunicações e Artes da ECA/USP. Coordenador do Núcleo de Comunicação e Educação do CCA/ECA/USP. Vice-Presidente do WCME World Council for Media Education. Fax: 011 - 81843 26. E-mail:ismar a usp.br.

Comun. Inf., v.1, n. 2, p. 229-233, jul./dez. 1998 


\section{0}

de todas as formas de expressão que deve estar presente no desenvolvimento do currículo e na gestão escolar".

Ao propor as "diretrizes para uma pedagogia de qualidade". o documento do CNE recomenda, por outro lado, um currículo voltado para as "competências básicas" a serem desenvolvidas pelos educandos. Nesse sentido, o signiticado da educação geral no nível médio, segundo o espírito da nova LDB, nada tem a ver com o ensino enciclopedista e academicista dos currículos de ensino médio tradicionais, reféns do exame vestibular. Ao contrário, deverá continuar o processo de desenvolvimento da capacidade de aprender, com destaque para o "aperfeiçoamento do uso das linguagens" como meios de constituição dos conhecimentos, da compreensão e da formação de atitudes e valores. Comenta o documento do CNE: "A LDB neste sentido é clara: em lugar de estabelecer disciplinas ou conteúdos específicos, destaca competências de caráter geral das quais a capacidade de aprender é decisiva. $\mathrm{O}$ aprimoramento do educando como pessoa humana destaca a ética, a autonomia intelectual e o pensamento crítico. Em outras palavras, convoca à constituição de uma identidade autônoma".

Ao normatizar a reorganização dos currículos, o CNE solicita a todos os sistemas de ensino e aos colégios que organizem seus procedimentos educativos e contéudos didáticos em três áreas de "Saberes" específicos: a Área de Línguagens e Códigos (e suas Tecnologias), a Área das Ciências da Natureza e Matemática. e a Área das Ciências Humanas.

$\mathrm{Na}$ área do saber específico denominado "Linguagens e Códigos" devem ser destacadas - segundo o documento - as competências que dizem respeito à constituição de significados que serão de grande valia para a aquisição e formação dos conteúdos curriculares, para a constituição da identidade e para o exercício da cidadania: "É importante destacar que o agrupamento das linguagens busca estabelecer correspondência não apenas entre as formas de comunicação - das quais as artes, as atividades físicas e a informática fazem parte inseparável como evidenciar a importância de todas as linguagens enquanto constituintes dos conhecimentos e das identidades dos alunos, de modo a contemplar as possiblidades artísticas, lúdicas e motoras de conhecer o mundo".

Exemplifica o documento, entrando no mérito da didática ou das práticas de ensino: "As competências da área da linguagem podem

Comun. Inf., v.1, n. 2, p. 229-233, jul./dez. 1998 
ser trabalhadas no contexto da comunicação na sala de aula, da análise da novela da televisão, dos diferentes usos da língua, dependendo das situações de trabalho ou da comunicação coloquial". Para o CNE, uma educação que não leve - através de uma leitura autônoma e contextualizada da comunicação - a uma reorganização das formas espontâneas de aprendizagem - parte delas geradas pela interação com os meios de informação - não será uma "educação que criou competências para abstrair de forma inteligente o mundo da experiência imediata".

O documento propõe que, no que diz respeito ao aprendizado dos códigos que dão suporte às linguagens, "não seja contemplado apenas o domínio técnico, mas especialmente a competência de desempenho". Defende o uso das linguagens em diferentes situações ou contextos, "considerando inclusive os interlocutores ou públicos". Mais adiante, o texto oficial orienta: "Ultrapassando o "discurso sobre as tecnologias', de utilidade duvidosa, é preciso identificar nas matemáticas, nas ciências naturais, nas ciências humanas, na comunicação e nas artes, os elementos de tecnologia que lhes são essenciais e desenvolvêlos como conteúdos vivos, como objetivos de educação e, ao mesmo tempo, meio para tanto".

No que toca à reordenação das grades curriculares, o documento do Conselho Nacional da Educação informa que devem ser previstas, nos vários anos que compõem o Ensino Médio, atividades que levem os educandos a:

- Entender os princípios das tecnologias da comunicação e da informação e associá-las aos conhecimentos científicos, às linguagens que lhe dão suporte e aos problemas que se propõem solucionar;

- Entender a natureza das tecnologias da informação como integração de diferentes meios de comunicação, linguagens e códigos, bem como a função integradora que elas exercem na sua relação com as demais tecnologias:

- Entender o impacto das tecnologias da comunicação e da informação na sua vida, nos processos de produção, no desenvolvimento do conhecimento e na vida social;

- Aplicar as tecnologias da comunicação e da informação na escola, no trabalho e em outros contextos relevantes para a vida.

O dispositivo está se referindo, pois, a âmbitos específicos de ação pedagógica, tais como: a) ao Emprego das Tecnologias Educacionais 


\section{2}

por parte dos docentes na otimização do ensino presencial e à distância: b) à Educação para a Comunicação, destinada à formação dos receptorese usuários dos meios e das tecnologias, no espaço mais abrangente da educação para a cidadania e, finalmente, c) à Capacitação para o uso das Tecnologias da Informação, tendo em vista a indispensável educação para o trabalho.

Indubitavelmente, fortalece-se o consenso de que uma adequada gestão da comunicação e da informação no espaço educativo, compreendendo, no mínimo, os três campos descritos. deixou de ser preocupação localizada de alguns poucos tecnólogos, transformando-se, ao contrário, em objeto de estudo e prática social, que aproxima de forma estreita e definitiva os mundos da Comunicação Social e da Educação.

\section{A formação do Educomunicador}

O Ministério da Educação e as próprias redes de ensino sofrerão duas ordens de problemas na implementação dos dispositivos que prevêem a introdução das linguagens e das tecnologias da comunicação no currículo do ensino médio: a) a redução de toda linguagem tecnológica à informática; b) a ausência de especialistas que assessorem os sistemas de ensino na implementação das medidas.

Quanto ao primeiro problema, recordamos que a expectativa criada pelas novas diretrizes curriculares é a de que, no caso do estudo das "linguagens e suas tecnologias", os alunos adquiram a necessária competência para "compreender e usar os sistemas simbólicos das diferentes linguagens", devendo o aluno "entender o impacto das tecnologias na sua vida pessoal, nos processos de produção, no desenvolvimento do conhecimento e na vida social". Como levar à prática os dispositivos legais, que pressupõem o estudo de todas as tecnologias da informação e de todas as linguagens da comunicação, se ao longo dos últimos anos o que se viu, no campo das tecnologias, foi uma concentração de esforços no campo específico da informática? Nesse sentido, o Plano Decenal de Educação do Governo Federal prevê a informatização das escolas, mas desconhece a necessidade de tornar acessivel outros recursos, especialmente na área da produção audiovisual. 
Quanto à segunda dificuldade, o próprio documento do MEC reconhece a inadequada formação dos professores para o ensino médio como a maior dificuldade para que se implemente a reforma anunciada. Acreditamos que a esta dificuldade deve ser somada outra: a insuficiente de especialistas na inter-relação Comunicação/Tecnologia/Educação dispostos a oferecer assessoria ao sistema educativo.

Os conselheiros do CNE reconhecem as dificuldades que o sistema de ensino terá para compreender e aplicar as novas normas, por conta especialmente da resistência de diretores, coordenadores e professores, ainda vinculados ao projeto tradicional e academicista de educação. Desse modo, propõem ao ensino superior que se abra para as novas necessidades de formação de quadros: "Do comportamento das universidades e outras instituições de ensino superior dependerá também, em larga medida, o êxito da concretização destas diretrizes curriculares para o ensino médio, com o qual elas mantêm dois tipos de articulação importantes: como nível educacional que receberá os alunos egressos e como responsável pela formação de professores". Trata-se, na verdade, de uma preocupação com a formação de profissionais em condições de promover e assegurar a reforma do ensino sob outras bases.

Nesta linha, apresentamos uma proposta: que o sistema educativo nacional possa contar com serviços de formação dos educomunicadores em toda Universidade que disponha de boas Faculdades de Comunicação e de Institutos ou Faculdades de Educação, através de projetos que dêem conta da complexidade e interdisciplinaridade da nova área. Por outro lado, que os comunicadores sociais vocacionados para o campo da educação se apresentem ao sistema educativo. Sua presença se faz necessária e urgente.

\begin{abstract}
The Ministry of Education has just disclosed the document entitled "The New Average Teaching" which is followed by the "National Curriculum Guidelines for the Brazilian Average Teaching", aproved by the National Council of Education, in june this year. Along with the new legal rules, the theme of the Communication/Technologies interrelation of Information/Education.
\end{abstract}

Key words: teaching of communication; curriculum guidelines; education technologies.

Comun. Inf., v.l, n. 2, p. 229-233, jul./de=. 1998 